\title{
Experimental and Numerical Analysis of the Energy Efficiency of Transparent Partitions with a Thermal Storage Unit
}

\author{
Michał Musiał' \\ 1 Rzeszow University of Technology, The Faculty of Civil and Environmental Engineering and Architecture, \\ 35-959 Rzeszów, ul. Poznańska 2, Poland \\ e-mail:mmusial@prz.edu.pl
}

\begin{abstract}
The article presents the results of experimental research and a mathematical analysis of the energy efficiency of a PCM-modified transparent partition. The study was carried out during the summer season and heating season for 5 months under temperate climate conditions in Rzeszów (Poland). The solution under investigation allows for short-term storage of heat within a building window, owing to the high value of melting/freezing enthalpy of approx. $185 \mathrm{~J} / \mathrm{g}$, and the phase change material (PCM) applied. The research was conducted in parallel over two identical windows, with only one of them being modernised with a phase change thermal storage unit. The obtained results showed the possibility of improving the thermal balance of the window by $9.99 \%$, and a more favourable adjustment of gains from solar radiation to the profile of heat demand of the adjacent room by $15.02 \%$, compared to the reference window. The obtained results also allowed the numerical model describing the non-stationary heat exchange within the phase change material to be verified, using the solution of a Stefan problem. The obtained model was created using the equations of finite difference method in the Matlab environment. The verified model is highly compatible with empirical quantities, and constitutes a useful tool for simulating the distribution of heat storage in a PCM storage unit over time. This allows the heat gains resulting from the use of the tested storage units in the building windows to be estimated.
\end{abstract}

Keywords: transparent building partitions, phase change material, thermal storage unit in window, thermal efficiency of building window, thermal balance of window

\section{INTRODUCTION}

The current trends in construction require that the new buildings be designed and the existing buildings upgraded to reduce their energy costs. A large part of these costs depends on the climate and purpose of the buildings, related to the need to heat and air-condition the spaces they contain. One of the solutions proposed in the scientific literature is to increase the thermal capacity of building partitions in order to make the heat conditions in the building more independent of the external climate. By using the phase change materials (PCMs) with a narrow range of phase change temperatures, the amount of energy corresponding to the product of the mass of the applied PCM and its phase change enthalpy can be stored temporarily (Vogel 2006;
Boussab et al. 2018; Mofijur et al. 2019; Chen et al. 2019; Tenpierik et al. 2019).

These materials are used in the construction industry, both as transparent and opaque partitions. Cascone et al. (2018) presented an analysis of the impact of PCM on the thermal functioning of the office buildings requiring the thermal upgrading. The variants based on two different PCMs, in a number of configurations of the application site (internal/external side of the opaque partition), were analysed. The parameter used to determine the thermal efficiency of buildings was the primary energy demand indicator. The results confirmed the validity of using PCM to thermally upgrade buildings, indicating the stabilising influence of PCM on the peak temperature values of the building partitions, which resulted in a reduction in the building heat demand. The weakness of the 
solution was the dependence of the upgrade success on the occurrence of the PCM phase change, which was only possible during the sunny days.

Transparent partitions are critical elements of a building thermal cover due to the amount of heat transmitted through them. Depending on the climatic conditions, they may permit the excessive cooling or overheating of rooms.

In order to prevent overheating of the rooms adjacent to the windows, shading systems, protruding hoods or glazing coatings are used, such as those presented in (Zhang et al. 2019) containing an admixture of antimony with tin oxide (ATO) and caesium-tungsten $\left(\mathrm{Cs}_{0^{3} 33} \mathrm{WO}_{3}\right)$

Due to their structure and function, transparent partitions are characterised by lower thermal capacity and higher heat transfer coefficients than opaque partitions. Therefore, the use of PCMs to improve the energy efficiency of windows is justified. Numerous scientific works presenting the upgrading of transparent PCM partitions (Lia et al. 2020; Li et al. 2018) show a reduction in the daily glazing surface temperature fluctuations and a reduction in the expenditures on interior heating in winter and cooling in summer. Paper (Liu et al. 2018) addresses the use of PCM in the interpane space of a multi-pane roof window. The research was conducted for the climatic conditions of north-eastern China. Different thicknesses of two PCMs with a phase transition enthalpy of $180-185 \mathrm{~J} / \mathrm{g}$ and melting/freezing temperatures of $16-18^{\circ} \mathrm{C}$ and $20-22^{\circ} \mathrm{C}$ were analysed. The results confirmed the energy benefits of PCM, with a melting point of $16-18^{\circ} \mathrm{C}$ and a thickness of 1.2-2.0 cm being the most effective solution. On the other hand, the thermal parameters of a semi-transparent solar wall, ensuring at the same time heat absorption and temporary storage, were studied in (Souayfan et al. 2018). The wall was made of a layer of glass, silica aerogel and glass blocks filled with organic PCM. The research work was conducted in Sophia Antipolis in southern France. The results of the experiment proved that the examined wall was more effective in winter than in summer. This is due to the excessive heat gains that were not stored in the PCM due to its long-term melting. In order to improve the energy performance of the numerical model of the wall in summer, the heat transfer mechanisms from the PCM to other building partitions were taken into account.

Other possibilities to improve the thermal functioning of windows include the application of PCM in the frames, blinds or louvres. In papers (Musiał 2019), the author presented the research confirming the desired impact of PCM on the thermal balance of the window partition and internal louvre. Nevertheless, the application of PCM of both organic and inorganic origin in the free state requires a secure coating, which is chemically inert and characterised with a thermal expansion similar to the PCMs. In (Musiał 2018; Lichołai and Musiał 2018), the author proposed a copolymer coating based on vinyl acetate and alkyl acrylates, which can be used for coating parts of alkanes, fatty acids and esters.

Heat storage with PCM is also used in heat exchangers and thermal storage units. These solutions function both in the long and the short term (Lissner et al. 2016). In their work (Constantin et al. 2015) analysed the possibility of storing heat in a conventional residential building exchanger by using PCM. An organic PCM in the form of paraffin was used. The results of the analysis showed an improvement in the convective heat exchange in the exchanger using PCM, in relation to a storage unit using water. However, given the often insufficient intensity of the heat exchange through conduction and radiation, the use of a material changing the state in the liquid/gas and gas/liquid configuration should be considered in these solutions. This would result in an increase in the heat storage potential by a factor of several dozen, depending on the substance, generating additional problems related to the applicability of such a solution and significant changes in the PCM volume due to evaporation and condensation.

In their paper (Kang et al. 2011), Kong et al. presented the results of the experiments conducted to determine the relations between the geometry of the heat exchanger and the parameters of the refrigerant of air-conditioning devices, the system stabilising the temperature inside the building, as well as the effectiveness of the storage and exchange of heat in the storage unit. The presented results showed that the heat transfer rate decreased with the increases in the refrigerant evaporation temperature. In addition, a decrease in the intensity of heat exchange was recorded with an increase in the $\mathrm{d} / \mathrm{h}$ ratio of the storage unit, due to a decrease in the speed of the evaporating refrigerant.

The thermal performance of the phase change materials can be described by solving a Stefan problem, the one-dimensional simplification of which is presented in (Smolec 2000). This 
method can be used for one-, two- and three-dimensional models of stationary and non-stationary heat transfer systems. It allows the amount of stored heat in a specific time step to be determined based on determining the position of the phase limit of the material under consideration. In accordance with (Smolec 2000), this method may be used, provided that a "sharp" phase change material is used.

Taking into account the information presented in (Kalinović et al. 2017), the specificity of the functioning of transparent partitions in the buildings presented in (Kalinović et al. 2017), as well as the specificity of the PCM and climatic conditions, the decision was made to test a solution using a quasi-box window as presented by Szyszka and Starakiewicz (2018) with an applied thermal storage unit containing the phase change material in order to determine the impact of the upgrade in terms of the energy efficiency over that of the reference window. It is a solution that can be used successfully in the newly designed buildings and to thermally upgrade the existing buildings. By creating a space between the two glazing units, it was possible to compensate for peak glazing temperatures during the sunny days. This reduced the heat loss during the night time compared to the conventional windows with a single glazing unit.

The desire to increase the ability to store the heat absorbed within the windows resulted in the need to test the window containing a unit to store the heat unit from the PCM in the space between the glazing.

\section{MATERIALS AND METHODS}

\section{Materials}

- RT28 phase change material by Rubiterm GmbH (https://www.rubitherm.eu/)

- $2 \mathrm{~mm}$ thick aluminium sheet, covered with a matt black paint coat.

- XPS extruded polystyrene panels, thickness $5 \mathrm{~cm}$, density $100 \mathrm{~kg} / \mathrm{m}^{3}$ and thermal conductivity $0,032 \mathrm{~W} / \mathrm{m} \cdot \mathrm{K}$.

\section{Apparatus}

- Almemo 2890-9 recorder.

- Comet MS6d | MS6R recorder.

- Pt1000 temperature sensor.

- Heat flux density sensor: FQA020 C.
- $\quad$ LT 019008 thermocouple.

- Almemo FLA 613 GS pyranometer.

\section{RESERCH METHOD}

The research was conducted in summer and the transitional heating period of an office and educational building of the Rzeszów University of Technology. Two windows were tested, located in the same room, facing south, each with two glazing units. A thermal storage unit containing RT28 PCM was placed in one of the windows. The storage unit was sited horizontally on a thermally insulated (5 cm XPS) sill surface within the space between the glazing units. The sill surface in the reference window was insulated in the same way. The results were recorded concurrently for each window, in 10-minute steps, including the temperatures and densities of the heat flux of the internal and external glazing units as well as the air temperature between the glazing units in each of the two windows. The temperatures of the aluminium casing of the thermal storage unit and the PCM within it, in addition to the temperatures of the internal and external air and the intensity of the solar radiation were recorded as well. This solution should increase the stabilising effect on the temperature values of the quasi-box window. At the same time, a storage unit containing 3.30 $\mathrm{dm}^{3}$ of PCM should be able to temporarily store heat from the conversion of solar radiation energy, which would not occur normally. In addition, the absorbent coating on the storage unit should increase its ability to convert solar energy into heat. This could then be used to partially protect adjacent rooms from overheating. A diagram of the test setup is shown in (Figure 1).

The thermal storage unit was made of $2 \mathrm{~mm}$ welded aluminium sheet, and measured $50 \mathrm{~mm} \mathrm{x}$ $100 \mathrm{~mm} \times 650 \mathrm{~mm}$. The dimensions of the storage unit were selected taking into account the dimensions of the space between the window glazing units, as well as the study intentions and analyses presented in (Musiał 2019; Musiał 2018) carried out by the author. In order to increase the ability of the storage unit to convert the energy of the Sun's radiation into heat, the unit was coated with a black matt paint. The selection of the phase change material used inside the storage unit took into account its physicochemical parameters and the thermal conditions occurring within the space between the window glazing units. Prior to the 


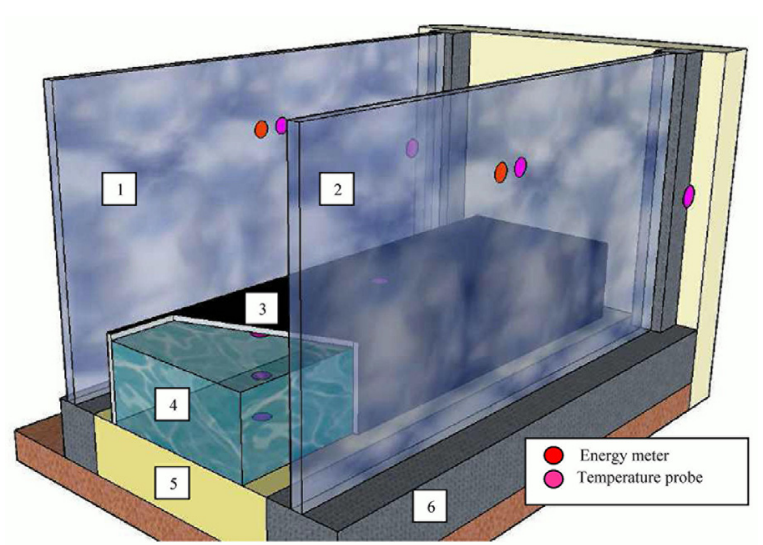

Figure 1. Diagram of the test stand. 1- exterior glazing, 2 - interior glazing, 3 - thermal storage unit, 4 - PCM, 5 - XPS thermal insulation, 6 - window frames

test, the thermal conditions within the windows were analysed, based on several weeks of preliminary measurements. A photo of the PCM thermal storage unit is shown in (Figure 2 and 3).

The expected functioning of this solution should result in the stabilisation of the daily temperature changes within the window with PCM compared to the window without. This could then translate into reduced daily air temperature changes in the room under consideration. This stabilisation of temperature changes should result from the impact of the buffer space, i.e. the air between the glazing units, based on the complex phenomena of multiple reflections of solar radiation during the sunny days, and the ability to absorb it from the PCM storage unit. The presence of a PCM heat storage unit with a melting point of approx. $27.5^{\circ} \mathrm{C}$ and a solidification point of $21.5^{\circ} \mathrm{C}$, covered with a reflective coating, was intended to additionally intensify the stabilising effect of the daily temperature fluctuations of the inter-pane space. Furthermore, due to the storage of large amounts of heat in the narrow

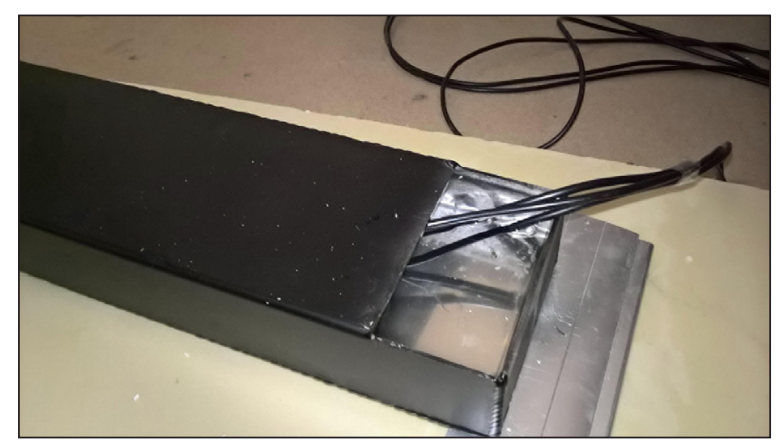

Figure 2. Thermal storage unit with RT28 PCM and Pt1000 sensors temperature range of approx. $6{ }^{\circ} \mathrm{C}$, the danger of overheating the PCM window in relation to the reference window should be reduced in relation to the changes in the air temperature between the glazing units. A functional layout of the solution is presented in (Figure 4).

The beneficial effect of the presented solution on the thermal functioning of building transparent partitions can be demonstrated by analysing the energy demand of a window with a thermal storage unit and a reference window without a thermal storage unit. In order to perform a thermal balance analysis of both windows, the internal pane glazing unit in both windows was chosen as the surface area for the heat exchange between the interior of the room and the external environment. The recorded density values of the heat flux as a function of time should allow the determination of the amount and direction of the heat transmitted by the glazing surface.

$$
Q_{w}=\int_{t=1}^{t=n} q_{t} d t
$$

where: $Q_{w}-$ heat transmitted through the partition during the analysed time

$q_{\mathrm{t}}$ - heat flux density recorded on the partition surface

$t$ - time

Another method of determining the energy efficiency of the PCM-based solutions is to determine the number of degree hours as a measure of the temperature difference between two points maintained over a given time period. For evaluating windows with a thermal storage unit, the difference in the sum of the daily degree hours of the internal glazing temperatures between the window with a PCM storage unit and the reference window is important in determining the window

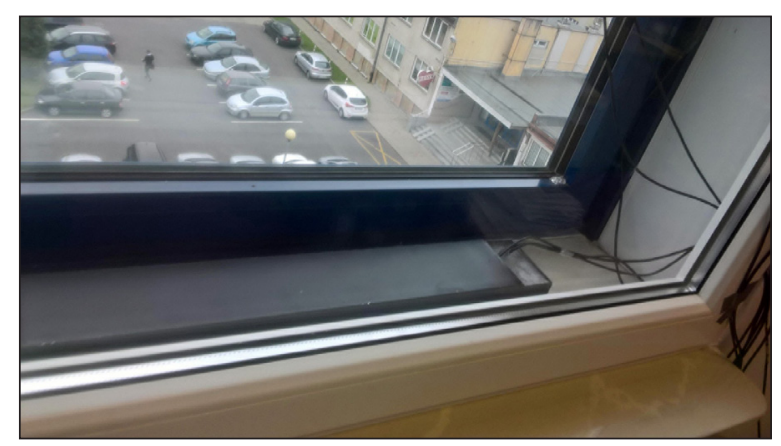

Figure 3. Thermal storage unit in the space between the glazing layers of a double-glazed window 

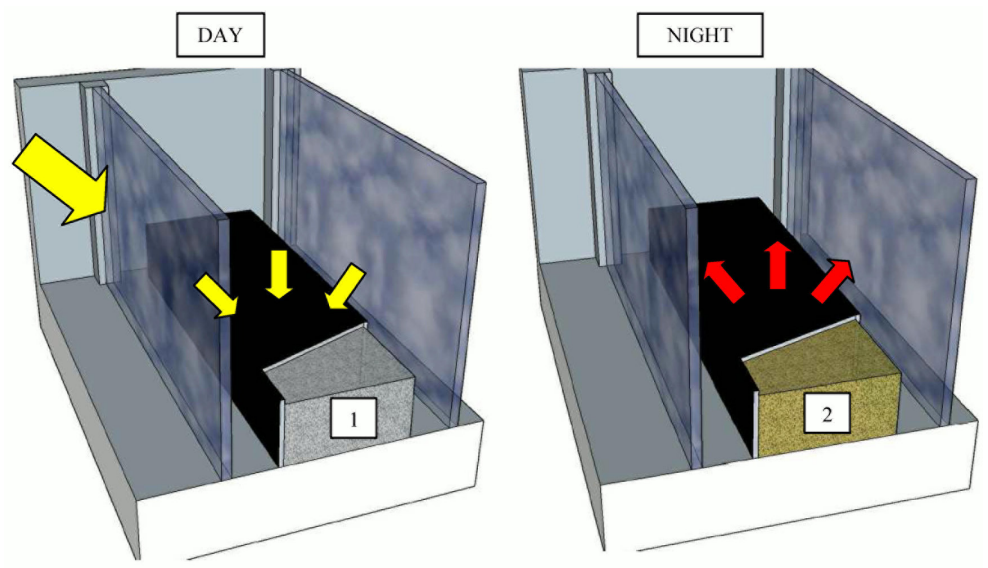

Figure 4. The functioning of a window with a PCM storage unit, day and night; 1 - solid PCM, 2 - liquid PCM

characteristics. The number of degree hours was determined by means of the formula:

$$
\mathrm{S}_{\mathrm{th}}=\int_{\mathrm{t}=1}^{\mathrm{t}=\mathrm{n}}\left(\mathrm{T}_{\mathrm{N}}-\mathrm{T}_{\mathrm{i}}\right) \mathrm{dt}
$$

where: $S_{\text {th }}-$ number of degree hours

$t-$ time

$T_{N}$ - temperature of the internal glazing surface

$T_{\mathrm{i}}-$ indoor air temperature

\section{Mathematical model - Stefan problem}

The determination of the efficiency of heat storage in the PCM used inside the storage unit, under different conditions of the external climate, was carried out by solving the Stefan problem according to (Smolec 2000). For the model of this procedure, Matlab 2018b was used, based on the equations of the finite element method, presented in (Kisilewicz 2009). For the purpose of this analysis, the equations of the one-dimensional model of heat transfer in a non-stationary system, as shown in (Figure 5), were applied.

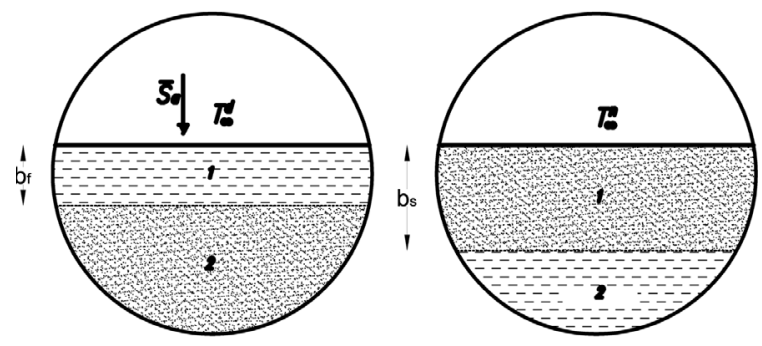

Figure 5. Operation diagram of a PCM storage unit with a sharp phase change (Smolec 2000), 1 - liquid PCM, 2 - solidPCM, $b_{f}$ - liquid PCM width, $\mathrm{b}_{\mathrm{s}}$ - solid PCM width

$$
\frac{\partial \mathrm{T}}{\partial \mathrm{t}}=\frac{\lambda_{\mathrm{f}}}{\mathrm{C}_{\mathrm{f}} \cdot \mathrm{Q}_{\mathrm{mzf}}} \frac{\partial^{2} \mathrm{~T}}{\partial \mathrm{x}^{2}} \quad \text { dla } 0<\mathrm{x}<\mathrm{X}
$$

where: $\lambda_{f}-\mathrm{PCM}$ heat transfer rate

$C_{f}$ - thermal capacity of the PCM

$\varrho_{m z f}-$ PCM density the change in the energy level of the PCM layer adjacent to the heat-absorbing surface for $x=0$ can be determined using the formula:

$$
-\lambda_{\mathrm{f}} \frac{\partial \mathrm{T}}{\partial \mathrm{x}}=\overline{\mathrm{S}}_{\mathrm{a}}-\mathrm{U}_{\mathrm{u}}\left[\mathrm{T}(\mathrm{x}=\mathrm{o}, \mathrm{t})-\mathrm{T}_{\infty}^{\mathrm{d}}\right]
$$

where: $U_{u}$ - storage unit heat loss factor

$S_{a}$ - additional heat flux

With the Stefan condition met, where on the surface of the phase boundary: $x=X$ fulfilled (Smolec 2000):

$$
\begin{aligned}
& \varrho_{m z f} \cdot \Delta H \frac{\partial X}{\partial t}=-\lambda_{f} \frac{\partial T}{\partial x} \\
& \text { i } \quad T_{\mathrm{x}}=\mathrm{T}_{\mathrm{pf}}
\end{aligned}
$$

The negligibly low specific heat values of the PCM in relation to its melting/coagulation enthalpy were omitted from the calculation. In order to simplify the mathematical model, a sharp PCM phase change was made at $T_{p f}$ temperature. Thus, the limit of both phases can be unambiguously defined, and equation (3) is solved for the following boundary conditions (Smolec 2000):

$$
\mathrm{T}(\mathrm{x}, \mathrm{t}=0)=\mathrm{T}_{\mathrm{pf}} \quad \mathrm{X}(\mathrm{t}=0)=0
$$

Taking into account the equations above and assuming that in the equilibrium state, where the PCM is in the liquid state, the dependence of its temperature on position $x$ is linear (with a sharp phase change), the temperature map in this part of 
the storage unit can be determined from the relation (Smolec 2000):

$$
\begin{gathered}
T(x, t)=T_{p f}+\frac{\bar{S}_{a}-U_{u}\left(T_{p f}-T_{\infty}^{d}\right)}{\lambda_{f}+U_{u} \cdot X(t)} \\
{[X(t)-x]}
\end{gathered}
$$

The thickness of the liquid phase layer $b_{f}$ after the charging time $t_{d}$ is $($ Smolec 2000$)$ :

$$
\begin{gathered}
\frac{U_{u}}{2 \lambda_{f}} b_{f}^{2}+b_{f}=\frac{t_{d}}{\varrho_{m z f} \cdot \Delta H} \\
{\left[\bar{S}_{a}-U_{u}\left(T_{p f}-T_{\infty}^{d}\right)\right]}
\end{gathered}
$$

Owing to the dependencies above, it is possible to determine the change in the amount of stored heat over time as well as the time of its charging and discharging. Taking into account the far-reaching simplifications of the model presented in (Smolec 2000) and the idealised sharp phase transformation of PCM, the above-mentioned calculation procedure can be used for high purity PCM.

\section{RESULTS}

The results demonstrated the changes that occurred in the temperature and density of heat flux over time. The values recorded concurrently in the window with the thermal storage unit and the reference window, are presented for each time period. The results refer to two seasonal periods: the transition period between the heating season and the summer season (beginning of April 2018) and the beginning of the summer season (June 2018). In both cases, the results from a 7-day period are presented, with the majority of sunny days.

\section{Results for the final period of the heating season}

The presented results prove the anticipated functioning of the thermal storage unit, as shown in (Figure 8), where the daily air temperature fluctuation between the glazing units in the PCM part was reduced compared to the reference part. The effect of the peak value decrease and phase shift in the graphs describing the PCM window in relation to the reference window is shown in (Figures 7 to 11). A summary of the daily heat

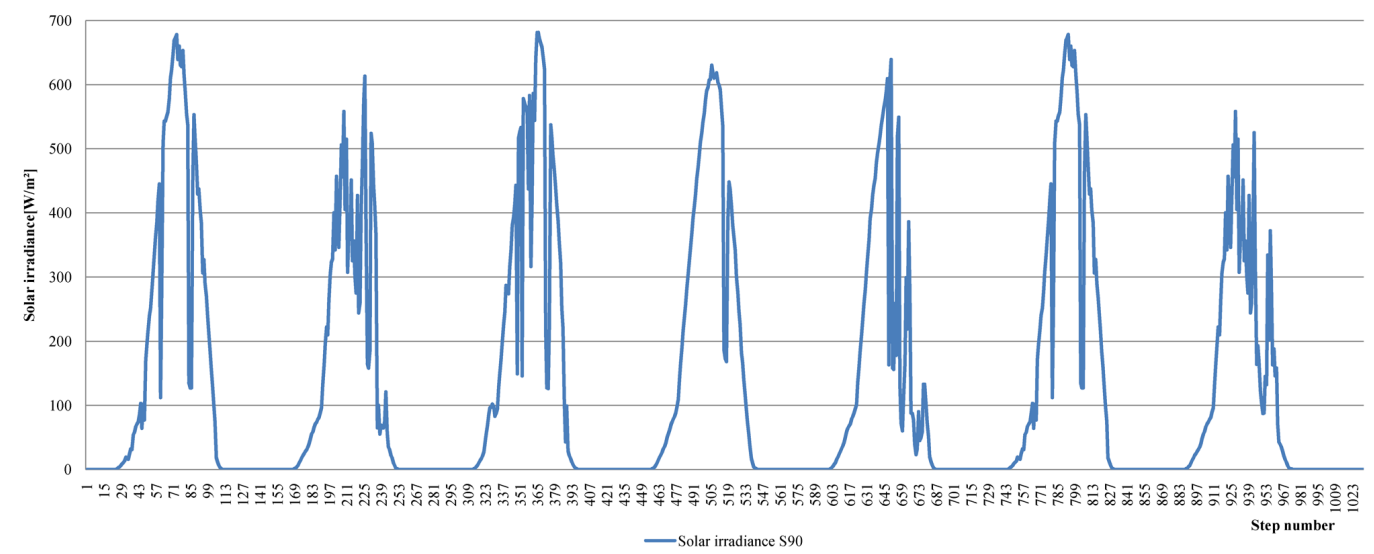

Figure 6. Graph of sunshine intensity

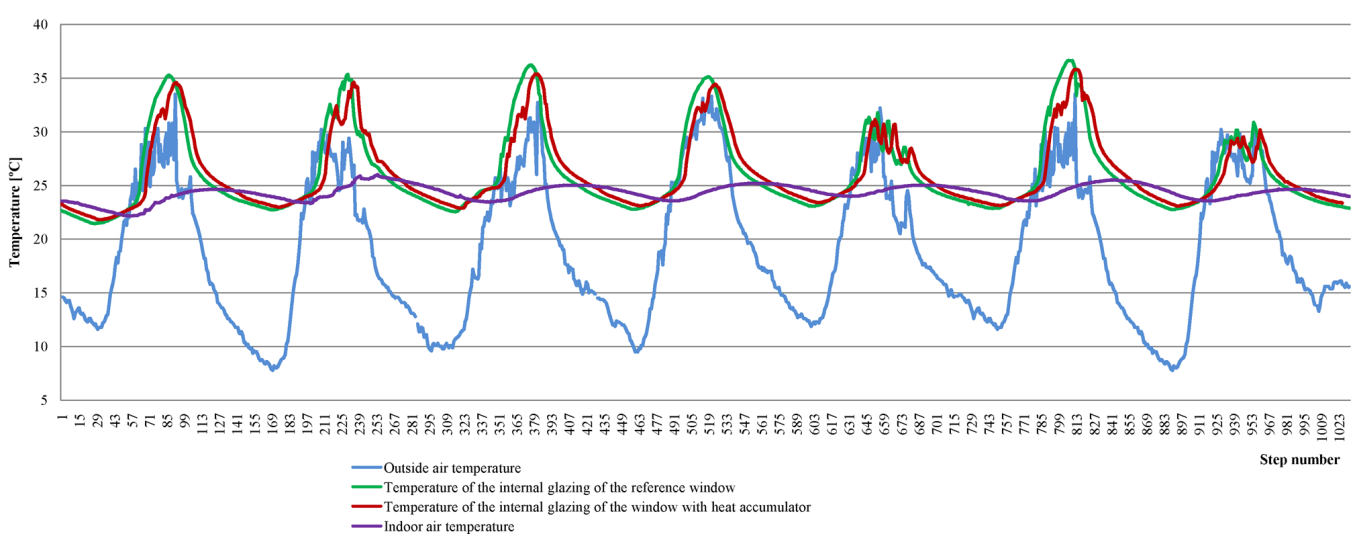

Figure 7. Graph of the internal temperature of the glazing units of the windows with and without the PCM storage 


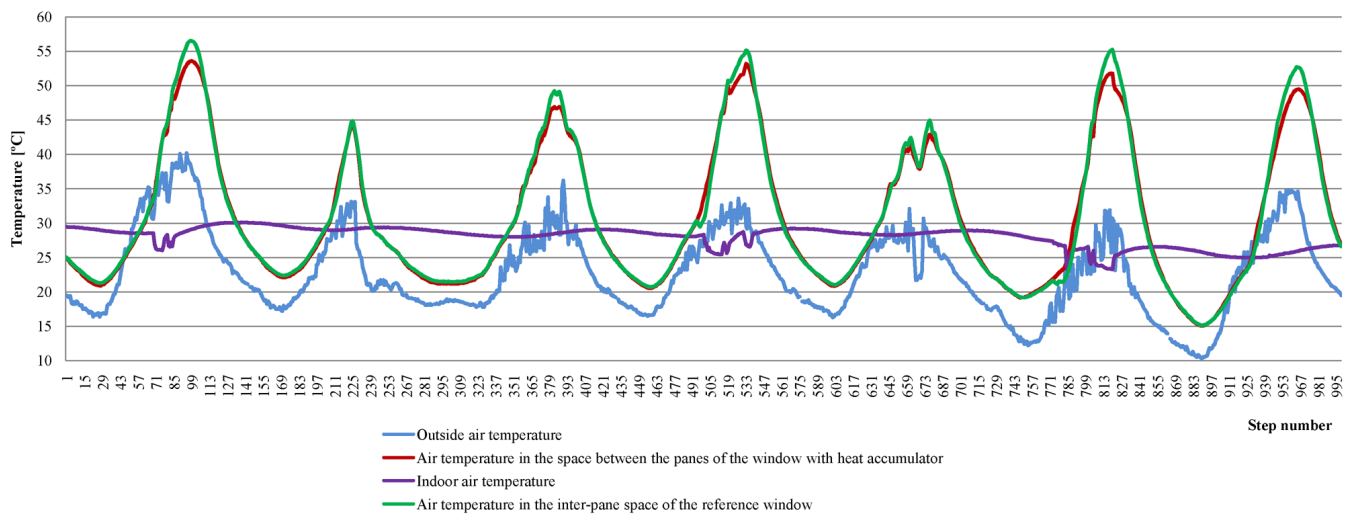

Figure 8. Graph of the density of the heat flux passing through the internal glazing units of the windows with and without PCM

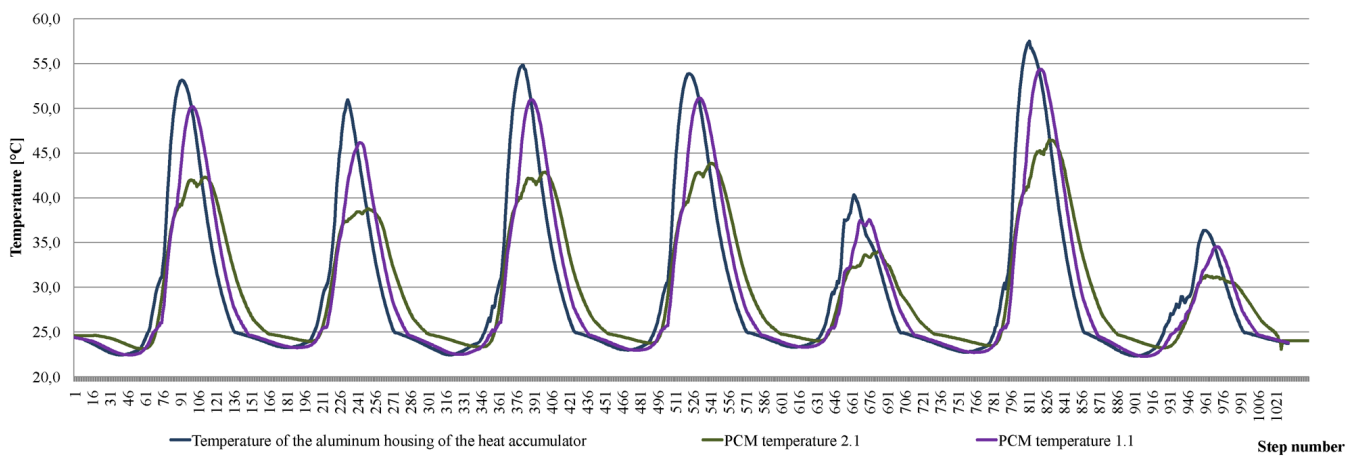

Figure 9. Temperature distribution diagram: thermal storage unit, PCM in point 1.1 (sensor mounted at $1 \mathrm{~cm}$ depth), PCM in point 2.1 (sensor mounted at $2 \mathrm{~cm}$ depth)

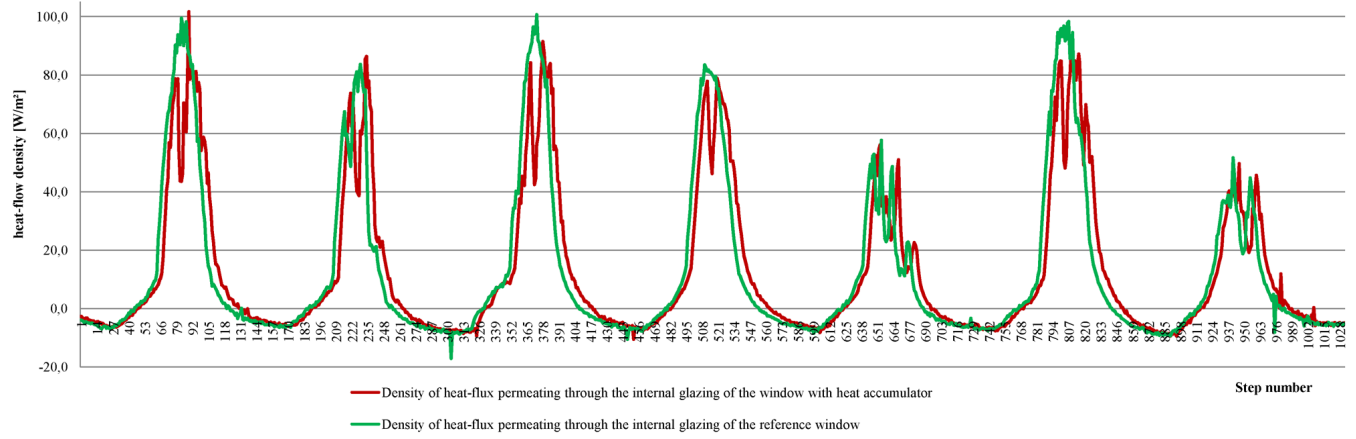

Figure 10. Graph of the air temperature of the inter-pane space in the glazing units of windows with and without the PCM storage

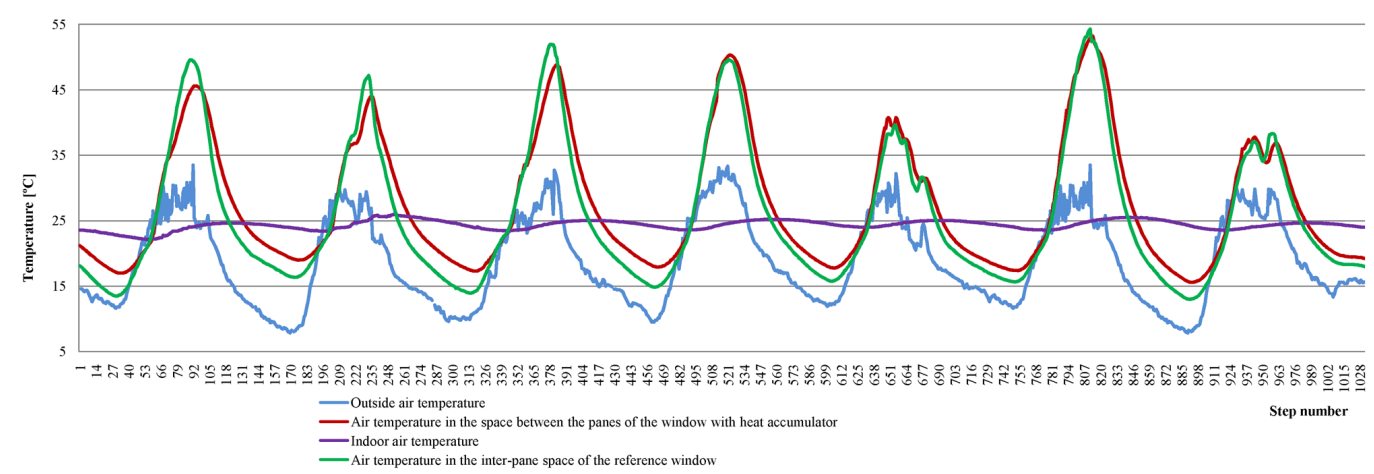

Figure 11. Graph of the temperatures of the external glazing of windows with and without the PCM storage 
Table 1. Summary of heat balance values and degree hours of the windows with and without PCM storage

\begin{tabular}{|c|c|c|c|c|c|}
\hline \multirow{2}{*}{ No. } & \multirow{2}{*}{ Solar irradiance $I_{s 90}$} & \multicolumn{2}{|c|}{ Heat balance of the internal window glazing } & \multicolumn{2}{c|}{ Number of degree hours } \\
\cline { 2 - 6 } & & with thermal storage & reference & with PCM storage & reference \\
\cline { 2 - 6 } & $\mathrm{Wh} / \mathrm{m}^{2}$ & $\mathrm{Wh}$ & $\mathrm{Wh}$ & $\mathrm{Kh}$ & $\mathrm{Kh}$ \\
\hline 1 & 3998 & 412.23 & 437.27 & 54.11 & 54.55 \\
\hline 2 & 2928 & 283.76 & 273.65 & 37.53 & 39.44 \\
\hline 3 & 3829 & 379.12 & 399.46 & 52.34 & 53.22 \\
\hline 4 & 3798 & 374.75 & 375.72 & 50.85 & 52.29 \\
\hline 5 & 2845 & 178.55 & 163.25 & 22.58 & 26.57 \\
\hline 6 & 3998 & 416.66 & 416.67 & 55.10 & 58.43 \\
\hline 7 & 2687 & 174.63 & 157.17 & 22.67 & 26.17 \\
\hline
\end{tabular}

balances and the degree hours of both windows is presented in (Table 1).

The results in (Table 1) indicate a decrease in the daily values of degree hours for the PCM storage unit window compared to the reference window. In the same period, an improvement in the daily heat balance of a window with PCM thermal storage compared to the reference window was recorded for only two days.

\section{Results for the summer period}

The data recorded for the windows over the summer period showed overheating of the storage unit with PCM, with (Figure 10) demonstrating almost identical courses of temperature change in the aluminium casing of the thermal storage unit and the PCM contained in it. The long-term overheating of the PCM enables its thermal functioning within the melting/solidification transformation. This phenomenon occurs when the PCM is still in a liquid state on a daily basis. This translates into the thermal functioning of other window elements. During the tests, a slight phase shift was noted in the graph of internal temperatures of the glazing of the window with the PCM storage unit compared to the reference window (Figure 13), along with a decrease in the air temperature peaks between the glazing units of the windows with and without the PCM storage (Figure 14).

\section{RESULTS OF THE MATHEMATICAL SIMULATION}

The calculation procedure used in accordance with point (Mathematical model - Stefan problem) allowed a numerical model to be created in the Matlab environment. The model was made using the equations of non-stationary heat flow in an open, one-dimensional system, according to the equations described in (Kisilewicz 2009). The length of the time step taken to build the model was 10 minutes, which corresponds to the frequency of the empirical data recording. The comparison of the empirical temperatures and those obtained from the distribution models at the thermal storage unit points under consideration is presented in (Figure 14).

\section{Analysis of results}

In order to verify the convergence of the results obtained from the mathematical model and those measured experimentally, an analysis of the scattering of the empirical and model values using the Quasi-Newton method was performed. The error function minimum was determined in the form of the sum of the squares of the differences of the PCM temperature values at selected points of the thermal storage unit, the experimentally measured $T_{e}(t)$, and the $T_{s}(t)$ obtained by means of the presented calculation method.

$$
\min y=\sum_{t=1}^{n}\left[T_{e}(t)-T_{s}(t)\right]^{2}
$$

Coefficient of determination:

$$
R^{2}=1-\frac{\sum_{t=1}^{n}\left(\hat{z}_{t}-\bar{z}\right)^{2}}{\sum_{t=1}^{n}\left(z_{t}-\bar{z}\right)^{2}}
$$

where: $z_{t}-$ actual value of variable $\mathrm{z}$ at time $t$,

$\hat{\mathrm{z}}_{\mathrm{t}}$ - theoretical value of the dependent variable,

$\overline{\mathrm{Z}}$ - arithmetic mean of the dependent variable. 


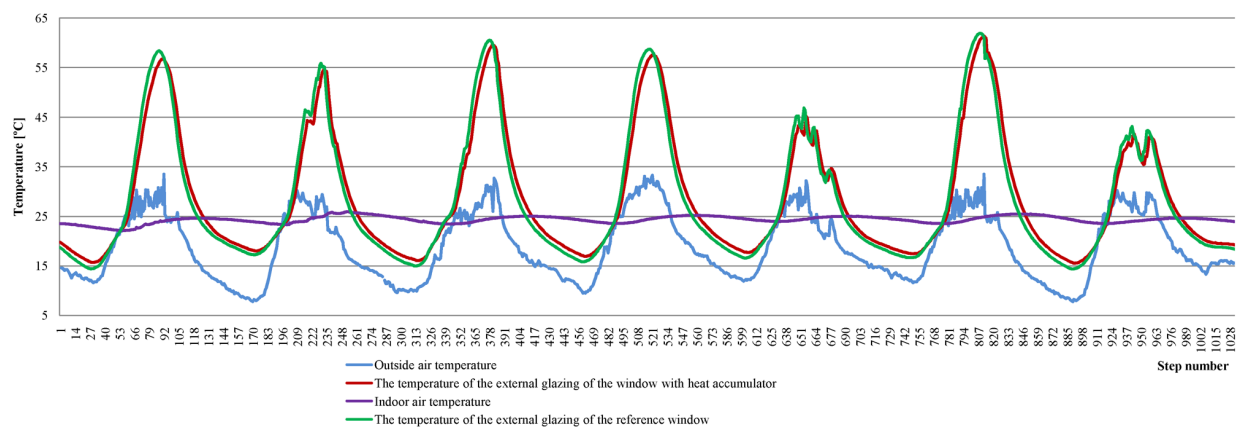

Figure 12. Graph of the temperatures of the thermal storage unit casing and the PCM contained in it during summer

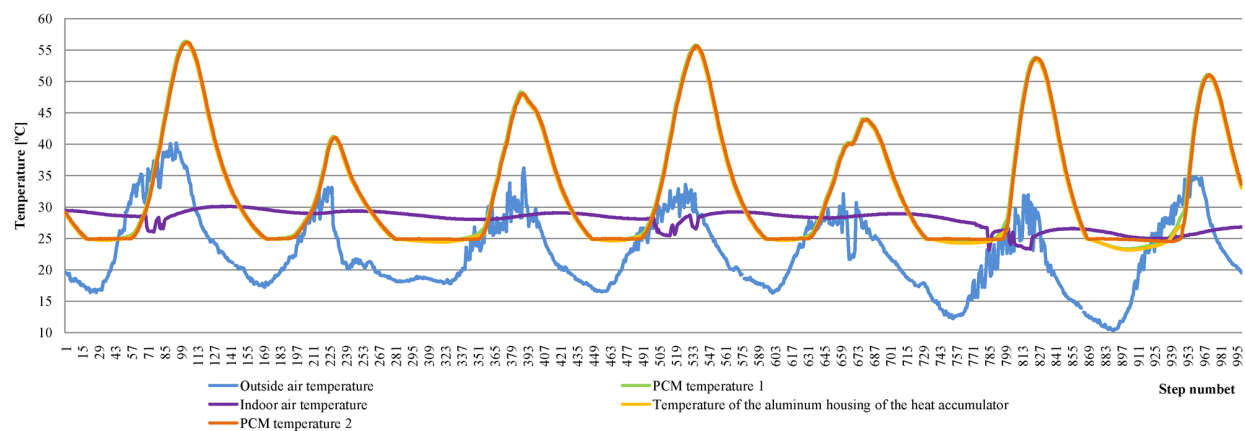

Figure 13. Graph of the temperatures of internal glazing of the windows with and without the PCM storage, in the summer period

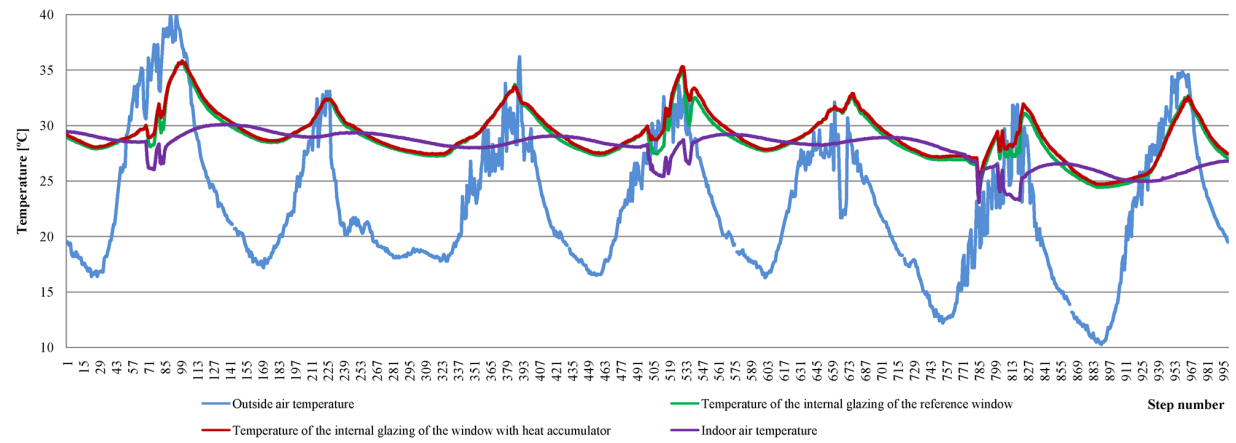

Figure 14. Graph of the inter-pane air temperature in the windows with and without the PCM storage, in the summer period
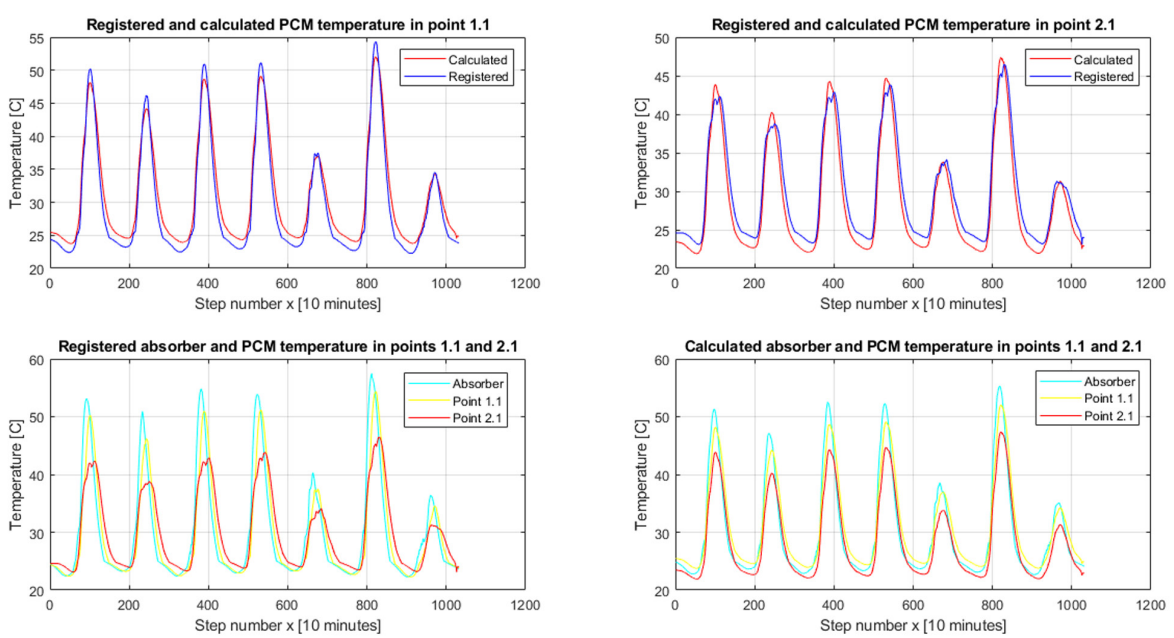

Figure 15. Charts compiling empirical and model temperature values of individual PCM storage unit points 


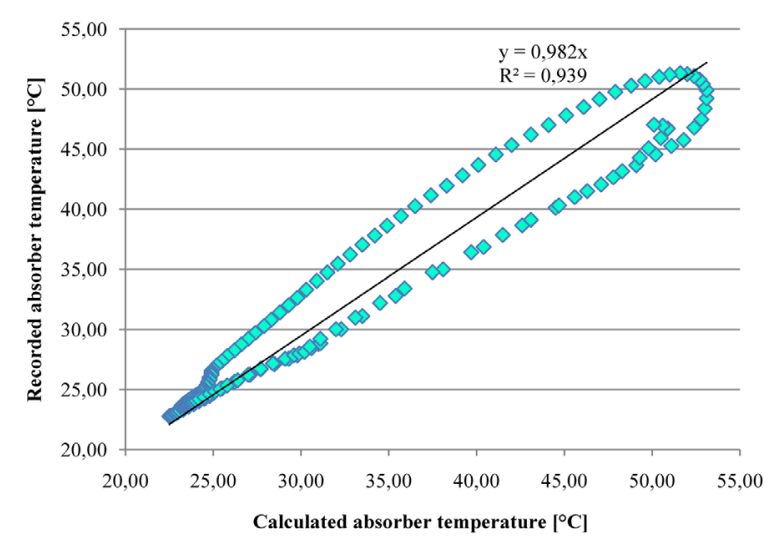

Figure 16. Fitting diagrams for empirical and model temperature values of the storage units

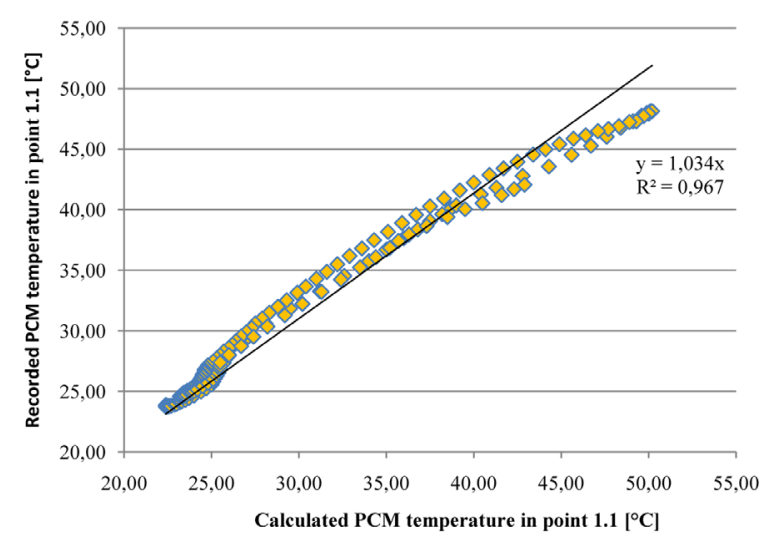

Figure 17. Model fit plots for empirical and model PCM temperature values in point 1.1 (at a depth of $1 \mathrm{~cm}$ into the storage unit)

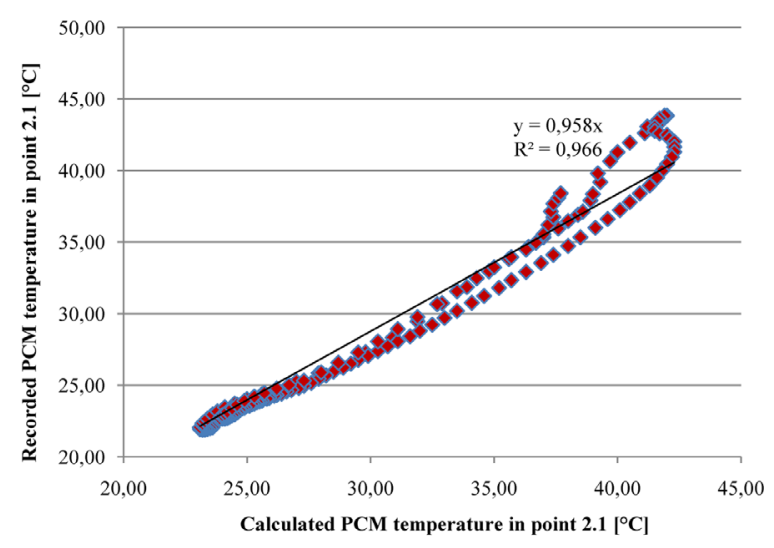

Figure 18. Model fit plots for empirical and model PCM temperature values in point 2.1 (at a depth of $1 \mathrm{~cm}$ into the storage unit)

One of the options of evaluating the fit of the measured values to the calculated ones is the determination of the relationship between them and the linear function $z=x$, shown in (Figures 16 to 18 ).
The results obtained for a randomly selected time period show a good match between the values obtained from the model and those recorded experimentally. This is evidenced by both high values of determination coefficients $R^{2}$, close to unity, and also similar values of the directional coefficient of function $z=a-x$.

\section{CONCLUSIONS}

The results from the heating season show that the window with the PCM thermal storage unit was able to achieve a daily heat balance that was 9.99\% more favourable than the reference window without a thermal storage unit. A $15.02 \%$ reduction was recorded in the number of degree hours during the sunny days in the heating season. For the cloudy days, the results for the PCM storage unit were not dissimilar to the thermal functioning of the window without storage, and contributed to an increase in the heat loss during such periods. For the tests during the summer period, the window with the PCM thermal storage unit did not show any significant changes in the values of daily heat balance or differences in the number of degree hours, compared to the reference window. Overheating of the thermal storage unit was observed during its operation inside the inter-pane space during summer. The reason for this was that the PCM temperature was maintained above its freezing point for extended periods. The evidence for the complete melting of the PCM in the summer period is the almost identical rate of PCM heating in different places inside the storage unit and its aluminium casing (Figure 10). In this case, heat storage only took place within the specific heat of the liquid PCM, as evidenced by the lowering of the air temperature peaks in the space between the glazing for the window with the storage unit relative to the reference window, without any visible slowdown in the temperature drop after sunset.

A numerical model made in the Matlab environment based on a simplified solution to the Stefan problem allowed for good mapping of the PCM temperature map inside the storage unit. This is evidenced by the similar unity of the values of determination coefficients, and the directional coefficients determined during the evaluation of the matching of the empirical values to the selected points inside the PCM storage unit obtained from the model. The verified model is 
a tool for determining the actual quantities of the heat stored and distributed within the PCM. This allows the potential heat gains associated with the use of a PCM thermal storage unit in building windows to be simulated. The proposed model can only be used for high frequency PCMs (characterised by sharp phase changes). For this reason, using a simple and relatively inexpensive solution reduces the energy costs of buildings during the transition period of the heating season.

\section{REFERENCES}

1. Boussab L., Foufa A., Makhlouf S., Lefebvre G. and Royon L. 2018. Elaboration and properties of a composite bio-based PCM for an application in building envelopes. Construction and Building Materials. 185, 156-165. doi:10.1016/j. conbuildmat.2018.07.098

2. Cascone Y., Capozzoli A. and Perino M. 2018. Optimisation analysis of PCM-enhanced opaque building envelope components for the energy retrofitting of office buildings in Mediterranean climates. Applied Energy. 211, 929-953. doi:10.1016/j. apenergy.2017.11.081

3. Chen X., Li X., Xia X., Sun C. and Liu R. 2019. Thermal Performance of a PCM-Based Thermal Energy Storage with Metal Foam Enhancement. Energies, 12, 3275. doi:10.3390/en12173275

4. Constantin L., Dragomir-Stanciu D. and Crismaru I. V. 2015. Optimization of Heat Exchange in a Heat Accumulator with Latent Heat Storage. Procedia Techology. 19, 737-741. doi.org/10.1016/j. protcy.2015.02.104

5. https://www.rubitherm.eu/index.php/produktkategorie/organische-pcm-rt \{access 23. 12. 2019\}

6. Kalinović M. S., Djoković M. J. and Nikolić R. R. 2017. Influence of windows geometrical parameters on calculations of the heat conduction coefficient. Procedia Engineering. 192, 404-409. doi. org/10.1016/j.proeng.2017.06.070

7. Kang H., Cho I., Park H. and Kim Y. 2011. Heat transfer characteristics of accumulator heat exchangers under various geometric and operating conditions. International Journal of Refrigeration. 34, 1077-1084. 10.1016/j.ijrefrig.2011.02.009

8. Kisilewicz T. 2009. A simple partition simulation model with transparent insulation, Technical Journal of the Cracow University of Technology, Z5-B/2009 87-94 [in Polisch]

9. Li S., Zou K., Sun G. and Zhang X. 2018. Simulation research on the dynamic thermal performance of a novel tripleglazed window filled with PCM. Sustainable Cities and Society. 40, 266-273. doi. org/10.1016/j.scs.2018.01.020
10. Lia D., Zhanga C., Lia Q., Liua C., Arıcıb M. and Wua Y. 2020. Thermal performance evaluation of glass window combining silica aerogels and phase change materials for cold climate of China. Applied. Thermal. Engineering. 165, 114547. doi: 10.1016/j. applthermaleng.2019.114547

11. Lichołai L. and Musiał M.2018. Use of copolymers of vinyl acetate and alkyl acrylates for coating organic phase change materials. Przemysł Chemiczny. 97/11, 1852-1854. doi:10.15199/62.2018.11.7

12. Lissner M., Tissot J., Leducq D. D., Azzouz K. and Fournaison L. 2016. Performance study of latent heat accumulators: Numerical and experimental study. Applied. Thermal. Engineering. 102, 604-614. doi. org/10.1016/j.applthermaleng.2016.03.011

13. Liu C., Wu Y., Bian J., Li D. and Liu X. 2018. Influence of PCM design parameters on thermal and optical performance of multi-layer glazed roof. Applied Energy. 212, 151-161. doi: 10.1016/j. apenergy.2017.12.012

14. Mofijur M., Mahlia T. M. I., Silitonga A. S., Ong H. C., Silakhori M., Hasan M. H., Putra N. and Rahman S. M. A. 2019. Phase Change Materials (PCM) for Solar Energy Usages and Storage: An Overview. Energies. 12, 3167. doi:10.3390/en12163167

15. Musiał M. 2019. Untersuchung des Einflusses der Geometrie von PCM-Elementen auf ihre Wärmespeichereffizienz. Bauphysik, 6/2019, 324-331 doi:10.1002/bapi.201900026

16. Musiał M. 2018. Use of organic aliphatic esters to obtain an energy - efficient eutectic mixture. Przemysł. Chemiczny. 97/11, 1855-1865. doi:10.15199/62.2018.11.8

17. Smolec W.2000. Photothermal solar energy conversion, PWN, Warsaw [in polisch]

18. Souayfan F., Biwol H. P. and Fardounb F. 2018. Thermal behavior of a translucent super insulated latent heat energy storage wall in summertime. Applied Energy. 217, 390-408. doi.org/10.1016/j. apenergy.2018.02.119

19. Szyszka J. and Starakiewicz A. 2018. A quasi-box window concept to improve the thermal-insulation property of old windows - case study. E3S Web of Conference SOLINA 2018. 49, 00115 doi: 10.1051/ e3sconf/20184900115

20. Tenpierik M., Wattez Y., Turrin M., Cosmatu T. and Tsafou S. 2019. Temperature control in (Translucent) phase change materials applied in facades: Anumerical study. Energies, 12, 3286. doi:10.3390/en12173286

21. Vogel A. J. 2006. Organic preparation, Warsaw. Scientific and technical publishing house. [in polisch].

22. Zhang W., Lu L. and Xu X. 2019. Thermal and daylighting performance of glass window using a newly developed transparent heat insulated coating. Energy Procedia. 158, 1080-1085. doi.org/10.1016/j. egypro.2019.01.262 